This PDF is a selection from a published volume from the National Bureau of Economic Research

Volume Title: Social Security Programs and Retirement around the World: Historical Trends in Mortality and Health, Employment, and Disability Insurance Participation and Reforms

Volume Author/Editor: David A. Wise, editor

Volume Publisher: University of Chicago Press

Volume ISBN: 0-226-90309-5; 978-0-226-90309-5

Volume URL: http://www.nber.org/books/wise11-1

Conference Date:

Publication Date: September 2012

Chapter Title: Disability Insurance and Labor Market Exit Routes of Older Workers in the Netherlands

Chapter Author(s): Klaas de Vos, Arie Kapteyn, Adriaan Kalwij

Chapter URL: http://www.nber.org/chapters/c12393

Chapter pages in book: (p. 419 - 447) 


\title{
Disability Insurance and Labor Market Exit Routes of Older Workers in the Netherlands
}

\author{
Klaas de Vos, Arie Kapteyn, and Adriaan Kalwij
}

\subsection{Introduction}

Earlier research suggests that the low participation rate of persons well below the statutory retirement age of sixty-five in the Netherlands can, at least in part, be attributed to generous incentives to retire (cf. Kapteyn and de Vos 1999). Until recently, the incentive to retire early was particularly strong if the employer offered an Early Retirement (ER) scheme, but an alternative route to retire via Disability Insurance (DI) was also quite attractive. A less attractive route to retire for workers is via Unemployment Insurance (UI) or Social Assistance (SA). The attractiveness of DI and its relatively easy access for elderly workers can be seen as significant contributing factors for the high prevalence of DI receipt in the Netherlands, as compared to most other developed countries. There is a large body of research showing that a considerable part of the DI recipients in the Netherlands are not really (totally) unfit to work (cf. Aarts and de Jong 1990). De Gier, Henke, and Vijgen (2003) conclude however that most of the results of this research have hardly affected DI policy making.

In this chapter, we aim to contribute to the knowledge on the relationship between DI and retirement by focusing on two questions. The first question is whether, next to or instead of the strong incentives to retire via DI, we can find indications that trends in health and mortality actually played a role in the increase of the numbers of DI recipients until the early 1990s and their

Klaas de Vos is a senior researcher in the Quantitative Analysis Department at CentERdata. Arie Kapteyn is a senior economist at the RAND Corporation. Adriaan Kalwij is assistant professor at Utrecht University and a research fellow at Netspar.

For acknowledgments, sources of research support, and disclosure of the authors' material financial relationships, if any, please see http://www.nber.org/chapters/c12393.ack. 
decrease since then. To that end, we will present various graphs relating health, mortality, DI receipt, and labor market participation.

The second question concerns the effect of reforms on DI and other income maintenance and early retirement programs on the number of older workers exiting the labor market and the pathways chosen to exit and effectively retire. To assess possible effects of reforms, we will present graphs that show the dates of various reforms in combination with the trends in the pathways to retirement. In addition, we will estimate a model in which the reforms to DI and other programs are included as explanatory variables for changes in the pathways to retirement.

The chapter proceeds as follows. Section 12.2 contains a brief overview of DI and other programs and a chronological overview of reforms during the past four decades. Section 12.3 presents graphs on health, mortality, DI, and labor force participation. Section 12.4 presents graphs on the pathways to retirement. Because the data on pathways only cover a limited period, section 12.5 presents a number of additional graphs covering a longer period. Section 12.6 aims to quantify the effects of reforms on the pathways to retirement. Section 12.7 concludes.

\subsection{Disability Insurance and Other Social Security Programs and Reforms}

\subsubsection{Disability Insurance (DI)}

Introduced in 1967, the Dutch Disability Insurance (WAO, Wet op de Arbeidsongeschiktheidsverzekering) aimed to insure employees against loss of earnings as a result of long-term inability to work as a result of illness or incapacity. If, after having been ill for a period of one year, the employee could not resume work, he or she would be entitled to an earnings-related DI benefit that could last until the employee reached the statutory retirement age of sixty-five.

Starting in the 1970s, the numbers of individuals on DI in the Netherlands showed a continuous increase until the 1990s. These numbers were much higher than expected when the new DI legislation was introduced and much higher than might be expected given the average health status of the population. In fact, in the mid-1970s, when unemployment was rising dramatically, the route to DI was generally used by employers as a path of least resistance to shed superfluous employees. For the employee, DI was both socially more acceptable and more attractive than UI, in particular because the benefit could be received until age sixty-five when the old-age pension would kick in.

\subsubsection{Reforms}

With the increase in the number of benefit recipients, expenditures on DI started to rise dramatically, and since the start of the 1980s, government 
policy has sought to reverse the trend of the ever increasing DI expenditures by various reforms to limit access to DI, increase the number of persons exiting DI, and lower the average DI benefit (see table 12.1).

In 1985, the replacement rate of DI was lowered from 80 to 70 percent in the wake of the recession of the early 1980s. This affected both new entrants to DI and "existing cases." In 1987, access to the full DI was limited for partially disabled unemployed new entrants. In the early 1990s, again government saw the need to do something about the high numbers of DI recipients, and this resulted in a series of measures: the duration of the full DI benefit was limited for new entrants younger than fifty, stricter disability criteria were introduced for entry into DI, and younger DI recipients were to be retested. For individuals younger than forty-five, the new disability criteria were to be used, and, for persons between forty-five and fifty, retesting was to be done on the basis of the old disability criteria. Mainly because most employees took out a private insurance to compensate for the shorter duration of the full DI benefit for younger persons, DI remained an attractive option. Next to limiting the access and the generosity of the benefit, policies were also introduced to shift the costs to firms with high numbers of employees exiting to DI. First, the costs of sickness benefits were charged directly to the employer for two to six weeks (1994), and later on for a full year preceding the exit to DI. Second, in 1998, experience rating was introduced: for large firms in particular, the DI contributions were partly based on the DI record of the firm in question. A high exit rate into DI resulted in higher contributions.

Because all these reforms did not succeed in substantially reducing the numbers of DI recipients, by 2002, the feeling was that enough was enough and the time had come for a more radical approach. As from 2002, during the year of sickness preceding exit to DI, employer and employee are jointly responsible for taking sufficient action for reintegration into the workforce. Moreover, this sickness period can be extended if insufficient reintegration measures have been taken. As from 2004, exit to DI only happens after two years of sickness, during which time the employer pays sickness benefits. As from 2006, the new DI law (WIA, Wet werk en inkomen naar arbeidsvermogen) makes a strict distinction between fully and permanently disabled and partially or temporarily disabled. The former receive a generous 75 percent of their previous earnings until age sixty-five (IVA, Inkomensvoorziening Volledig Arbeidsongeschikten). The latter receive a less generous benefit (WGA, regeling Werkhervatting Gedeeltelijk Arbeidsongeschikten), which depends on the previous earnings, the number of weeks worked before, and the current earnings (if any) and the percentage of previous earnings that the employee is deemed to be capable of earning. Furthermore, once again, a retest procedure is set up for existing DI beneficiaries younger than fifty (whose DI remains unchanged).

All in all, despite the decreased generosity of the benefit, for a long time, DI remained an attractive route to exit the labor force, and while the levels of 
Table 12.1 Timeline of reforms to Disability Insurance (DI), State Pension (SP), Early Retirement (ER), Occupational Pension (PP), and Unemployment Insurance (UI)

\begin{tabular}{|c|c|c|}
\hline & $\mathrm{DI} /$ (long-term) sickness insurance & SP, ER, PP, UI \\
\hline 1967 & $\begin{array}{l}\text { Introduction of DI (WAO; 20,000 beneficiaries } \\
\text { expected) }\end{array}$ & \\
\hline 1974 & & $\begin{array}{l}\text { SP: Benefit raised and linked to net minimum } \\
\text { wage }\end{array}$ \\
\hline $1975-82$ & & $\begin{array}{l}\text { ER: Gradual introduction by sector/firm/ } \\
\text { department; } 1980 \text { ER contribution tax } \\
\text { deductible }\end{array}$ \\
\hline 1985 & $\begin{array}{l}764,000 \text { beneficiaries, replacement rate reduced } \\
\text { from } 80 \% \text { to } 70 \%\end{array}$ & $\begin{array}{l}\text { UI: Replacement rate reduced to } 70 \% \\
\text { SP: Married women get independent claim }\end{array}$ \\
\hline 1987 & No more (full) DI for (partially) unemployed & $\begin{array}{l}\text { UI: Changes in eligibility and benefit period; } \\
\text { earnings-related benefit followed by } \\
\text { continuation benefit } \\
\text { SP: Distinction between married and } \\
\text { cohabiting couples abolished; introduction } \\
\text { single parent allowance }\end{array}$ \\
\hline 1988 & & $\begin{array}{l}\text { SP: Earnings tested supplement when partner is } \\
\text { younger than } 65\end{array}$ \\
\hline 1991 & & UI: Eligibility revised \\
\hline 1993 & $\begin{array}{l}\text { (i) Persons younger than } 50 \text { receive DI for a } \\
\text { limited period } \\
\text { (ii) Stricter disability criteria } \\
\text { (iii) Retesting of younger DI recipients }\end{array}$ & \\
\hline 1994 & $\begin{array}{l}\text { Introducing employer-paid periods of sickness } \\
\text { (2-6 weeks) }\end{array}$ & SP: Earnings tested supplement adapted \\
\hline 1995 & & $\begin{array}{l}\text { UI: Eligibility revised, introduction short-term } \\
\text { benefit }\end{array}$ \\
\hline 1996 & $\begin{array}{l}\text { (i) Sickness benefit privatized: employer pays } \\
70 \% \text { of earnings ( } 1 \text { year) } \\
\text { (ii) Exemptions for earnings tested supplement } \\
\text { abolished }\end{array}$ & \\
\hline 1998 & $\begin{array}{l}\text { (i) Introduction of (limited) experience rating } \\
\text { DI contributions employer } \\
\text { (ii) Public employees included in DI }\end{array}$ & \\
\hline $2000-05$ & & $\begin{array}{l}\text { ER/PP: Trend toward actuarially fairer flexible } \\
\text { ER age }\end{array}$ \\
\hline 2001 & & UI: Public employees included \\
\hline 2002 & Stricter reintegration rules in case of sickness & \\
\hline 2003 & $\begin{array}{l}\text { Experience rating for small employers } \\
\text { abolished }\end{array}$ & UI: Abolition of continuation benefit \\
\hline 2004 & $\begin{array}{l}\text { (i) Sickness benefit period extended to } 2 \text { years } \\
\text { (ii) Strict reevaluation DI recipients younger } \\
\text { than } 50\end{array}$ & \\
\hline 2006 & $\begin{array}{l}\text { Introduction of new DI: strict distinction } \\
\text { between partially and fully, permanently } \\
\text { disabled }\end{array}$ & $\begin{array}{l}\text { ER: Fiscal friendly treatment of ER } \\
\text { contributions repealed; introduction of life } \\
\text { course saving } \\
\text { UI: benefit period shortened, higher benefit } \\
\text { first two months }\end{array}$ \\
\hline 2008 & Experience rating DI abolished & \\
\hline
\end{tabular}

Main source: Kroniek van de sociale verzekeringen 2008, www.uwv.nl.

Note $:$ WAO $=$ Wet op de Arbeidsongeschiktheidsverzekering. 
DI expenditures as a percentage of gross domestic product (GDP) have been decreasing considerably since the early 1980s, the number of DI recipients peaked much later, in the mid-1990s. Only the most recent series of major reforms, starting in 2002, appears to have resulted in a clear downward trend in the numbers of DI recipients.

\subsubsection{Other Programs}

As mentioned in the preceding, DI benefits end when the recipient turns sixty-five. More in general, the Dutch benefit system is characterized by a clear distinction between benefits for persons younger than sixty-five and benefits for persons aged sixty-five or above. The latter receive the flat rate state pension (SP), in most cases supplemented by an occupational pension (PP). The former may be entitled to Disability Insurance (DI), Unemployment Insurance (UI), means-tested Social Assistance (SA), or, when having retired before age sixty-five from a firm offering an occupational pension plan, an Early Retirement benefit (ER).

Early Retirement was introduced in most sectors during the 1970s, mainly in reaction to rising unemployment (cf. Kapteyn, de Vos, and Kalwij 2010) and, at least until the end of the 1990s in most cases, consisted of an offer too good to refuse. In particular, workers retiring later than the earliest possible ER date were not compensated by higher benefits or lower taxes so that, in fact, they faced an implicit tax rate of more than 100 percent (cf. Kapteyn and de Vos 1999).

For workers approaching sixty who were not entitled to ER (e.g., because of an insufficiently long employment history or because they worked in a firm that did not offer ER) and who could not plausibly be retired via DI, Unemployment Insurance (UI) offered a third pathway to retirement before the statutory retirement age of sixty-five. In most cases, it offered a replacement rate of 70 percent, and, furthermore, until recently, no obligation to search for employment after the age of 57.5.

Upon reaching the age of sixty-five, all residents are entitled to the flat rate state pension (AOW), which is financed by a pay-as-you-go social insurance contribution. Moreover, most employees accumulate fully funded occupational pension rights and supplement their state pension to (ideally) 70 percent of previous earnings.

Notably, traditionally in the Netherlands, substantial numbers of women used to leave the labor market (long) before age sixty-five without an earnings replacing benefit. In recent decades, labor market participation of older women has increased rapidly, and this pathway to retirement has become less common.

\subsubsection{Reforms to Other Programs}

The prospect of exploding costs once the large baby boom cohorts start to reach the ER age turned out to be sufficiently threatening for effective 
reforms to be put in place by the end of the 1990s. In most cases, a cost reduction as a result of reducing the effective ER entitlement was combined with the introduction of a more or less actuarially fair system. As a result, the employee could still opt for retiring early, but with a reduced pension, or later, but with an increased pension. By 2006, the government dealt a final blow to the old ER systems by effectively terminating the tax exemption for ER contributions that would enable a retirement age lower than sixty-five. Only systems offering a replacement rate of at most 70 percent at the pension age of sixty-five, and actuarially fair reductions when an earlier pension age is chosen can still collect tax exempt contributions. This reform does not affect workers who are already close to sixty-five and have accumulated more generous entitlements.

The Dutch Unemployment Insurance (UI) system saw a major reform in 1987, affecting both eligibility and benefit period. However, since 1984, workers aged 57.5 or older could receive UI until the state pension age of sixty-five, and this did not change in 1987. As of 2004, persons aged 57.5 or older receiving UI are no longer exempt from the requirement to seek work. In other words, they are no longer "automatically" receiving UI until age sixty-five but have to try to find work and, in theory, accept a job offer. Moreover, as of October 1, 2006, the maximum duration of UI is thirtyeight months. After that period, all that is left is a means-tested entitlement to Social Assistance (SA) with a benefit equal to the net minimum wage.

By and large, since 1974, for most single individuals and couples older than sixty-five, changes in the flat rate state pension are indexed by changes in the after tax minimum wage. Revisions include the introduction of an independent pension entitlement for married women in 1985 and the entitlement of supplementary state pension for persons with a spouse younger than sixty-five (1987, revised 1994). A proposed legislation to increase the statutory pension age by two years (to sixty-seven) by 2025 is still in discussion.

In addition to the universal right of a state pension from the age of sixtyfive onward, an increasing number of persons reaching the age of sixty-five (approximately 96 percent of men and 67 percent of women in 2007. See Knoef, Alessie, and Kalwij 2010) have been accumulating supplementary defined benefit occupational pension rights (PP). However, since the early 2000 s, the generosity of these occupational pensions has gradually been reduced because most of the pension funds have shifted from calculating the pension on the basis of final earnings to calculations based on average earnings. Moreover, in general the indexation of the benefits, which used to be based on the wage index, has become less generous following the successive crises on the stock market, affecting the investments of pension funds. Recently proposed pension reforms aimed at ensuring a sustainable Dutch pension system are still in discussion (cf. Stichting van de Arbeid 2010). 


\subsection{Historical Data: Mortality, Health Measures, Labor Force Participation (LFP), and Disability Insurance (DI)}

In this section, we address the first question formulated in the introduction on whether we can find indications that trends in health actually played a role in the increase of the numbers of DI recipients until the early 1990s and their decrease since then. For this purpose, we present statistics on labor force participation, the use of DI, self-reported health, and mortality rates of the population. These statistics point to the conclusion that there is not much of a relationship between the numbers of persons using DI and the general health of the population.

\subsubsection{Mortality}

We present three types of figures on mortality. Figures 12.1 (men) and 12.2 (women) take the mortality rates at age sixty and sixty-five of 1960 as their starting point and show the ages with the same mortality rate in the period up to 2008. For men, the age of equal mortality was actually lower than in 1960 until the early 1980s. From 1970, it shows an increase of more than seven years up to 2008. For women, unlike for men, the age of equal mortality did not show a clear decrease in the 1960s. However, on balance, the increase up to 2008 was only marginally larger than that of men.

Consistent with the findings in figures 12.1 and 12.2, figure 12.3 shows that both sexes saw their two-year mortality rates decline between 1960 and 2007, especially at higher ages. The decrease of the mortality rate for older women was substantially larger than that of men.

Figures 12.4 and 12.5 show the time paths of mortality rates for men and women ages fifty-five, sixty, and sixty-five, respectively. They confirm that

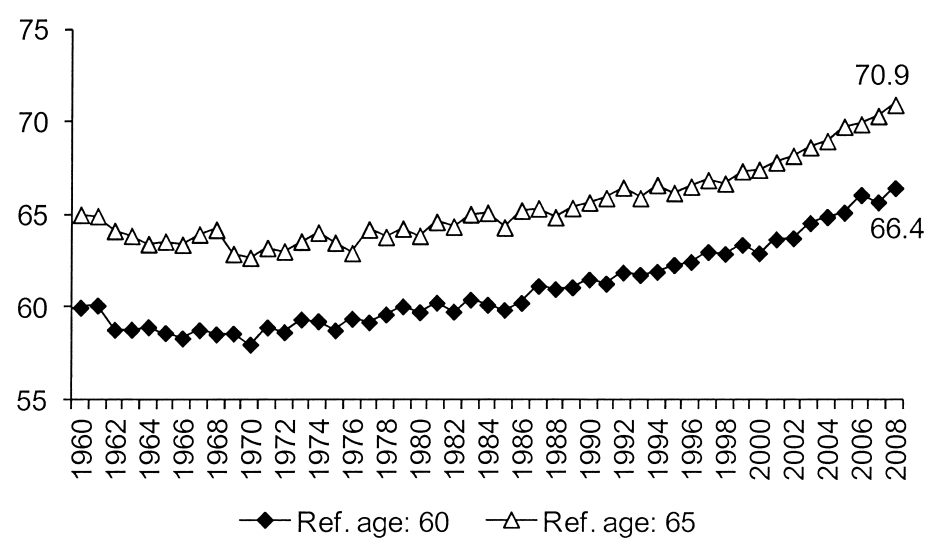

Fig. 12.1 Ages of equal mortality probability in the Netherlands for men, 1960 to 2008 


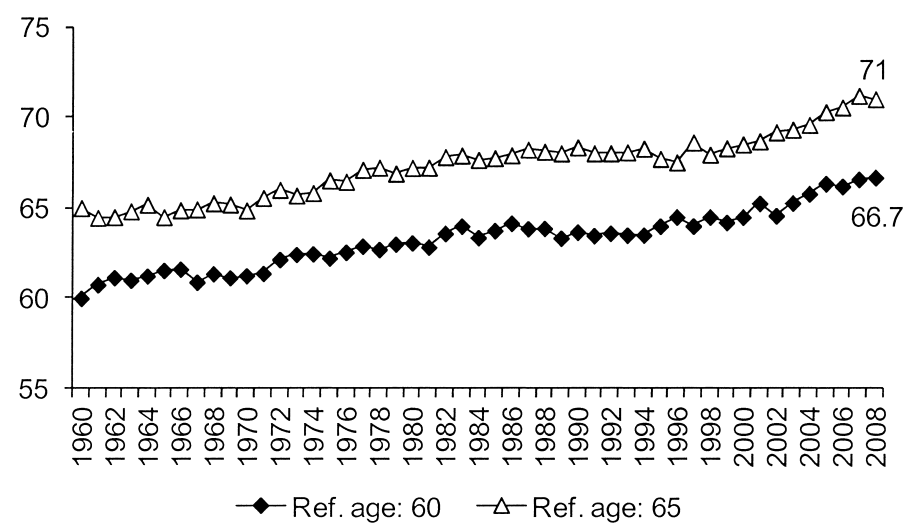

Fig. 12.2 Ages of equal mortality probability in the Netherlands for women, 1960 to 2008

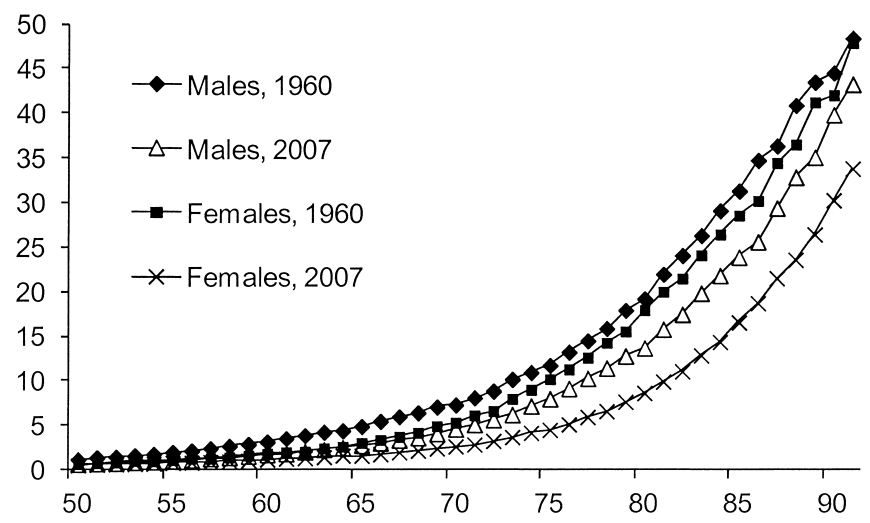

Fig. 12.3 Two-year mortality rate in the Netherlands by age and sex, 1960 and 2007

for men, mortality in 1980 was about equal to mortality in 1960 , but it also shows a clear decrease between 1970 and 2008. Women show a more uniform decline, starting from much lower levels.

\subsubsection{Mortality and Health}

None of the figures on mortality would lead one to suspect that, starting in the 1970s, the Netherlands saw an unprecedented increase in the numbers of disability benefit recipients and that, in fact, until recently, the Netherlands had one of the highest levels of DI receipt in the world. Conceivably, however, the introduction of a generous DI system may have contributed to the marked fall in male mortality during this period. Apart from mortality, not many health statistics can be found that can be used to track health over time. One of the few health statistics that is more or less comparable over a 


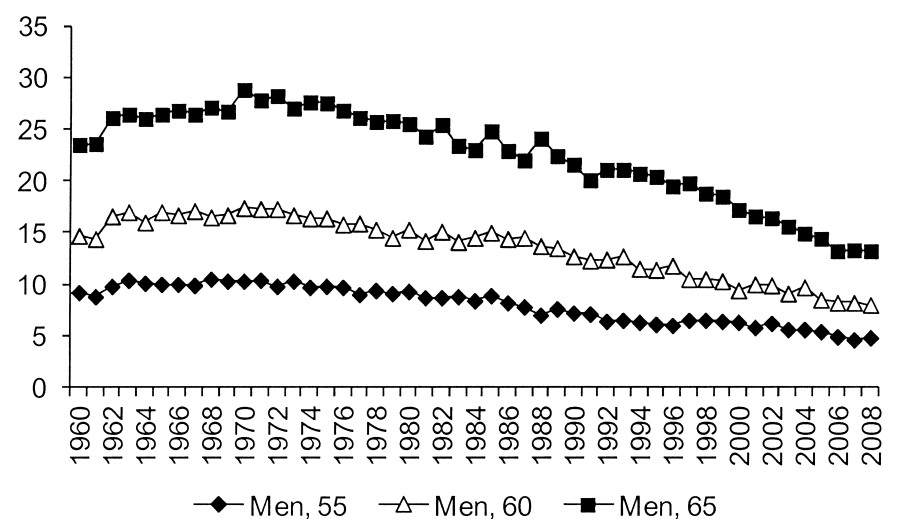

Fig. 12.4 Male mortality (/1000)

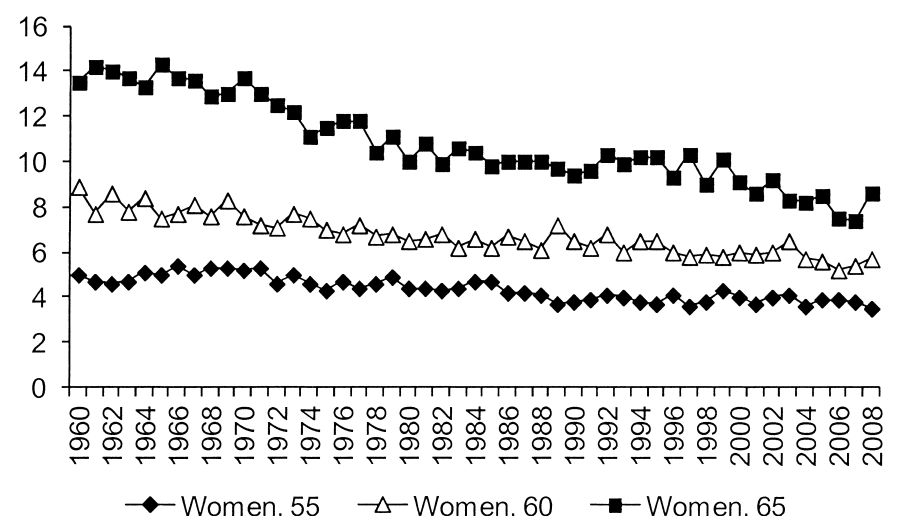

Fig. 12.5 Female mortality (/1000)

fairly long period of time is the series of self-reported good health collected by the Organization for Economic Cooperation and Development (OECD), available from 1983 until 2008. For both men and women aged forty-five to sixty-four, this statistic shows a somewhat erratic pattern (figures 12.6 and 12.7). For men, we observe on balance an increase in the percentage reporting good health or better between 1983 and 1995 and, with a few exceptions, a fairly stable rate (of about 75 percent) since then. For women, there is even less of a trend, and, in most years, the percentage of women reporting a good health or better hovers around 70 percent.

\subsubsection{LFP and DI versus Mortality}

It appears from figures 12.6 and 12.7 that self-reported health and mortality do not show a clear (negative) correlation. However, neither self-reported health nor mortality show a clear relation with DI prevalence or labor force 


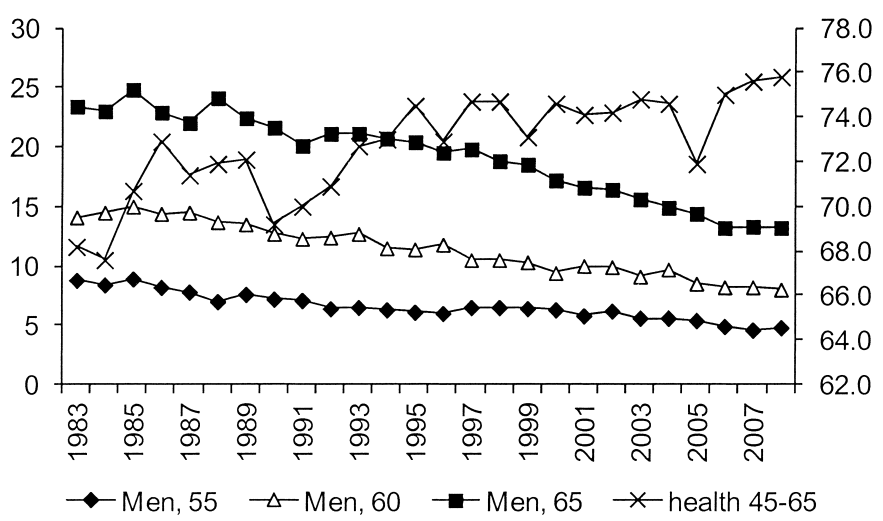

Fig. 12.6 Male mortality (/1000, left axis) and self-reported good health (\%, right axis)

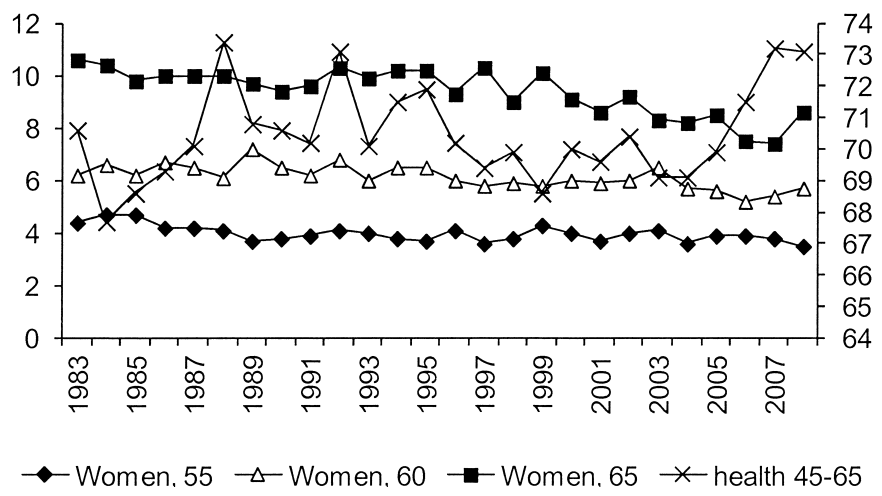

Fig. 12.7 Female mortality (/1000, left axis) and self-reported good health $(\%$, right axis)

participation either. As an example, we show employment and disability for men aged sixty to sixty-four in one figure with mortality at age sixty and sixty-five (figure 12.8) from 1981 until 2007. For women, we present the same information in figure 12.9.

For men, the continuous decrease in the mortality rates has been accompanied by decreasing employment and increasing disability prevalence during the first part of the period and increasing employment and decreasing disability since approximately 1995 . For women, decreasing mortality rates accompany more or less stable employment and somewhat increasing DI during the first half of the period and rapidly increasing employment and stable DI prevalence during the second half of the period. It is hard to interpret these patterns just based on health trends. During the first part of the period, one could argue that the increase in DI receipt has contributed 


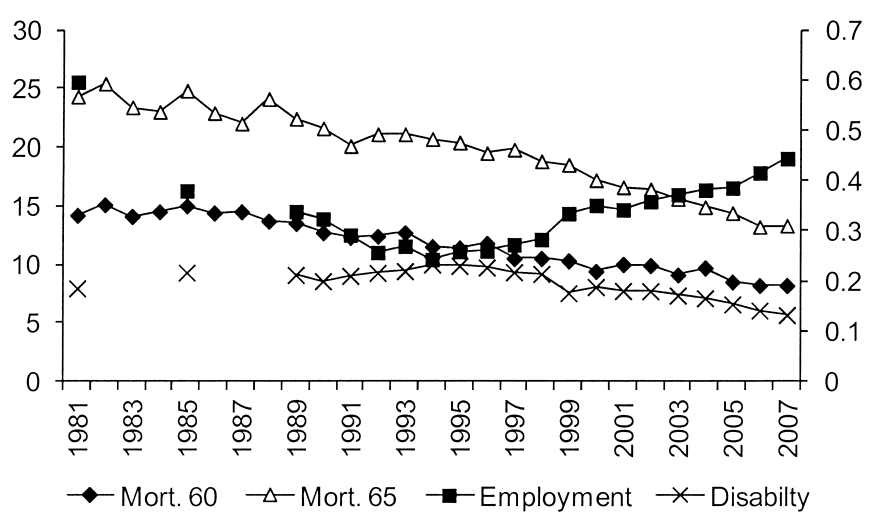

Fig. 12.8 Male employment and disability (\%, left axis) versus mortality (/1000, right axis), aged sixty to sixty-four

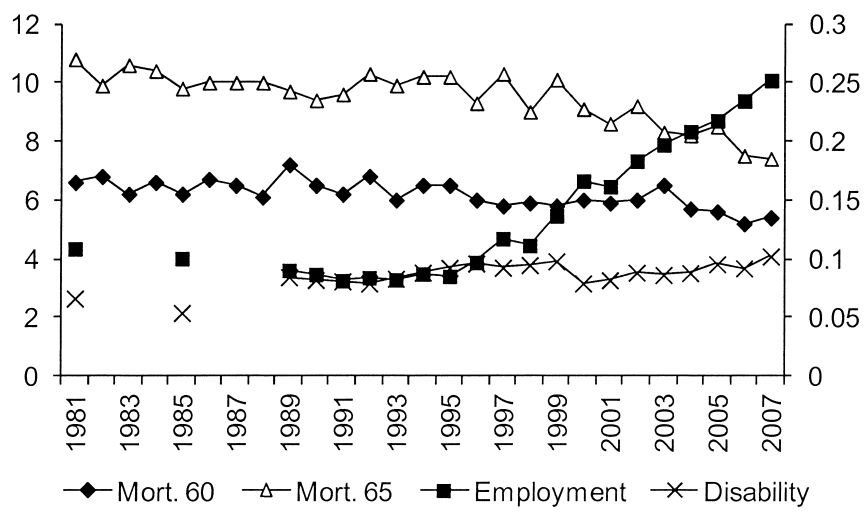

Fig. 12.9 Female employment and disability (\%, left axis) versus mortality (/1000, right axis), aged sixty to sixty-four

to longer lives, by allowing workers an escape from jobs that are detrimental to health. During the second part of the period, however, we see that both mortality and DI receipt are falling, so then we would have to assume that causality has changed direction and that a healthier population (at least for the male population) has less need to apply for DI benefits. Altogether, it seems more plausible that the changes in DI receipt are largely the result of the various reforms discussed before. It is to the effects of these reforms that we now turn.

\subsection{Pathways to Retirement and Program Reforms}

In this section, we address the second question formulated in the introduction and assess to what extent reforms in DI and other income maintenance 
and early retirement programs have affected the pathways to retirement and the labor force participation of the population approaching the retirement age. Detailed data on the pathways to retirement are only available for a relatively short period (1989 to 2007). Therefore, we will also present some results that do not depend on the availability of pathways data (section 12.5). The focus of the present section is the information on the pathways to retirement from the Income Panel Survey, which we first briefly describe in the following.

\subsubsection{IPO Data}

The data are taken from the 1981, 1985, and 1989 to 2007 Income Panel Study of the Netherlands (IPO [Inkomens Panel Onderzoek], Centraal Bureau voor de Statistiek [CBS] 2009) gathered by Statistics Netherlands. The IPO, a representative sample of the Dutch population, consists of an administrative panel data set of, on average, about 95,000 individuals per year. Sampling is based on individuals' national security numbers, and the selected individuals are followed for as long as they are residing in the Netherlands on December 31 of the sample year. The data set includes individuals living in institutions for the elderly, such as nursing homes. Individuals born in the Netherlands enter the panel for the first time in the year of their birth and immigrants to the Netherlands in the year of their arrival. An individual only exits the panel by death or emigration from the Netherlands. The IPO contains data on the demographic characteristics, income, and labor market status for each member of a selected individual's household.

\subsubsection{IPO Definitions of Labor Market Status}

The IPO income data are based primarily on records from the tax office and institutions that pay out (insurance) benefits and contain detailed information on all income components at an individual level. Based on the largest income component, Statistics Netherlands assigns a labor market status to an individual. An individual can be (self-)employed, unemployed (UI, receives unemployment insurance or social assistance benefits), on disability (DI, receives disability or [long-term] sickness insurance benefits), early retired (ER, when receiving pension income), or nonparticipating (NP, no labor income, pension, or benefits). ${ }^{1}$

\subsubsection{Policy Reforms}

In the figures presented in the following and in the next section, we indicate the dates of the main reforms in DI and other income maintenance and

1. The disability insurance scheme is referred to as WAO or WIA and the (long-term) sickness insurance scheme as ZW (see www.uwv.nl). Data limitations prevent a more refined classification. For instance, if an individual is partially disabled and the main source of income is from employment, this individual is classified as employed. 
early retirement programs from 1980 onward. More specifically, we indicate the following reforms:

- 1985: a reduction in the DI and unemployment benefits replacement rates from 80 to 70 percent

- 1993: stricter DI eligibility criteria

- 1996: introduction of one-year sickness benefits paid by employer before entering DI

- 1998: introduction of experience rating of DI contributions by employers

- 2000: actuarially fairer adjustments of ER pensions.

- 2002: Stricter gatekeeping for DI

- 2004: introduction of two-year sickness benefits paid for by employer before entering DI.

- 2006: several reforms introduced at the same time, with strict distinctions between partial, full, and permanent disability, a shortening of the UI benefit period, and the abolition of fiscal-friendly treatment of ER contributions

As discussed in section 12.2, table 12.1 provides a complete overview of reforms.

It needs to be noted that there have been a more or less continuous series of Social Security reforms in the various programs since the early 1990s, and it is, therefore, hard to assess whether some of the trends we will discuss in the following can be attributed to particular reforms. In addition, business cycle fluctuations may blur the pictures, and we return to this issue in section 12.6.

\subsection{4 (Self-)Employment}

We start with two figures presenting the employment rates (including selfemployment) for men and women in three age groups (fifty to fifty-four, fifty-five to fifty-nine, and sixty to sixty-four). Notably, the employment rate of older persons (sixty-five+) can be assumed to be fairly negligible in the Netherlands.

Figure 12.10 illustrates the dramatic decline in the employment rate of older men as well as the reversal of this trend starting about 1995. The pattern is particularly striking in the age group sixty to sixty-four, where the employment rate dropped from almost 60 percent in 1981 to less than 25 percent in 1994 and then picked up to more than 40 percent by 2007 . For women, on the other hand, we hardly observe decreasing employment rates (see figure 12.11). On the contrary, in the group of women aged fifty to fifty-four, the employment rate has been increasing since 1985, and the older age groups followed this trend some years later. Notably, at the end of the observation period, in all three age groups, the employment rate is still substantially below the figure for men.

As mentioned in the preceding, given the almost continuous series of 


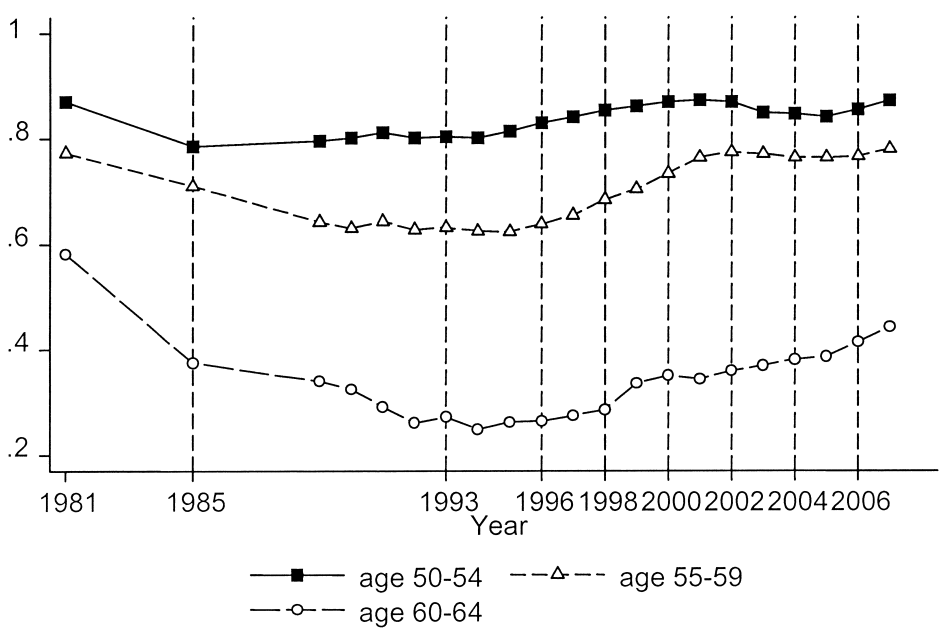

Fig. 12.10 Male employment rate by age group

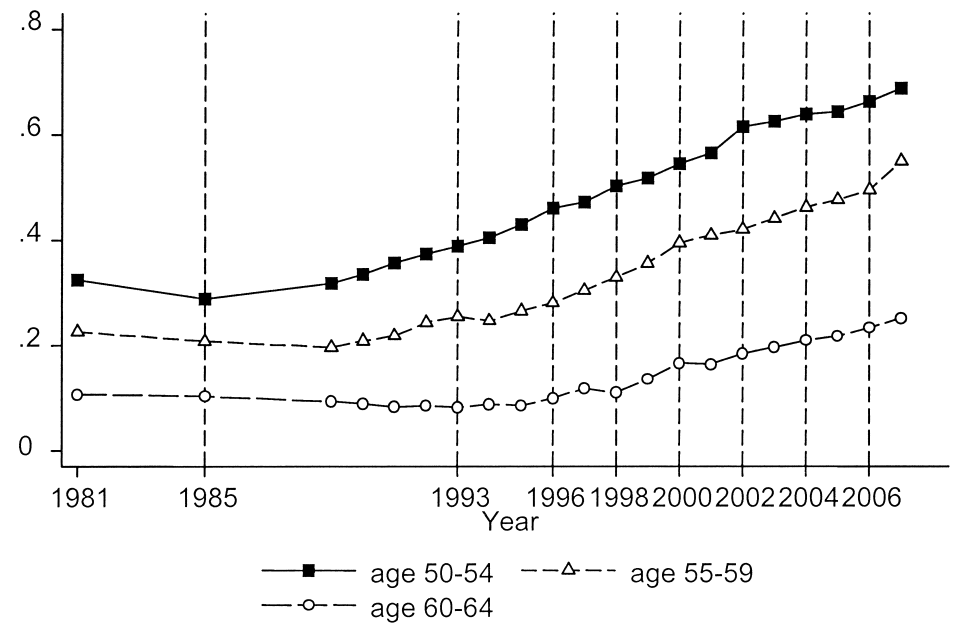

Fig. 12.11 Female employment rate by age group

reforms since 1993, it is hard to assess whether some of the changes in employment may be attributed to particular reforms. It can be assumed that at least part of the increase in the employment rate of older men would not have been observed if the implicit incentives to enter the respective retirement programs (ER, DI, UI) would have remained as generous as they were in the early 1990s. Cohort effects underlie large parts of the increases in the employment rates for women. However, here we can also assume that the employment rate would have been lower if access to DI, ER, and UI would not have been made more difficult and financially less attractive. 


\subsubsection{Pathways to Retirement}

Did the reforms affect the pathways to retirement? Undoubtedly, they did. However, it is difficult to distinguish the effects of reforms from other factors causing variation in the pathways. Moreover, even if the pathways remain stable, reforms may have effects on retirement (if, e.g., everyone chooses to retire one year later, the distribution across pathways may remain unchanged). Figures 12.12 and 12.13 show the pathways to retirement of men and women aged fifty to sixty-four between 1989 and 2006. A pathway

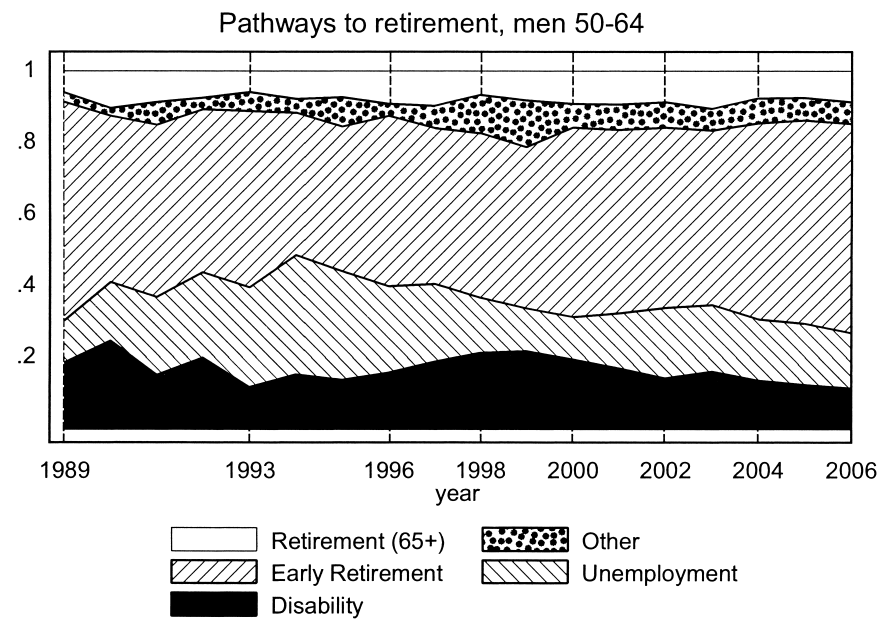

Fig. 12.12 Pathways to retirement, men, aged fifty to sixty-four

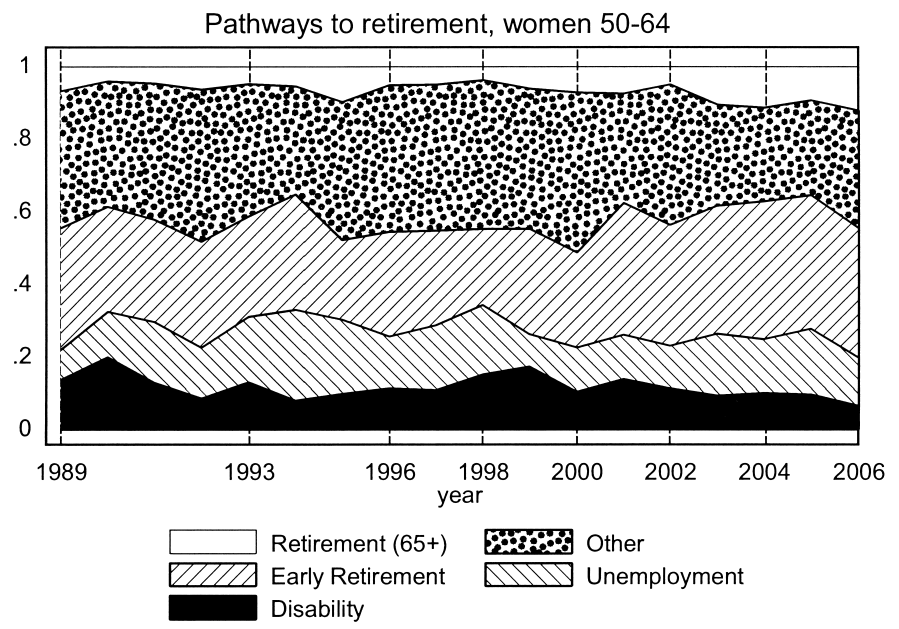

Fig. 12.13 Pathways to retirement, women, aged fifty to sixty-four 
is a particular exit route from employment between two subsequent years. For example, figure 12.12 shows that about 20 percent of the male workers aged fifty to sixty-four in 1989 who leave the labor market that year are on DI in 1990.

Looking at these figures, we see that the pattern is fairly stable given the many reforms to DI and other Social Security programs during this period. Nevertheless, some trends can be observed. Over this period, DI becomes a relatively less frequently used pathway to retirement for both men and women, in particular from the late 1990s onward. For men, ER is the dominant route to retirement throughout the whole period. The year with the lowest share of ER (and the highest share of unemployment) is 1993, a year with low economic growth and rapidly increasing unemployment. For women, leaving the labor market without own source of replacement income ("Other") and relying on the income or pension of the spouse remains a popular pathway to retirement but has been overtaken by ER. ${ }^{2}$ This is likely due to changes in the rules of the occupational pension schemes and the increased participation in terms of hours of work. For both men and women, retirement at the statutory retirement age of sixty-five remains quite exceptional. Unemployment and Disability Insurance together make up 30 to 40 percent of the pathways to retirement of the persons retiring in any given year among men and about 20 to 25 percent among women.

\subsection{Historical Data on Activity and Health}

\subsubsection{Employed, Unemployed, Not in the Labor Force}

In this section, we present labor force data for three age groups (forty to forty-four, fifty to fifty-four, and sixty to sixty-four) for men and women for the period 1981 to 2007 on the basis of the Income Panel Survey of Statistics Netherlands (see section 12.4). Figures 12.14 and 12.15 present employment rates, figures 12.16 and 12.17 unemployment rates, and figures 12.18 and 12.19 present the complement of employment and unemployment: not in the labor force.

For men, we once again note the steep decline of the employment rate in the older age group (sixty to sixty-four), from almost 60 percent in 1981 to less than 25 percent in 1994, picking up to more than 40 percent in 2007. Unemployment peaked at less than 15 percent in this age group in the 1990s, so, for the most part, the decline and subsequent increase in employment was complemented by a considerable increase in the percentage of men not in the labor force, peaking at more than 60 percent in 1994 and showing a clear decrease to less than 50 percent in 2007. The other two age groups

2. In fact, recipients of a state pension (sixty-five +) are entitled to a supplement if they have a younger spouse without income. 


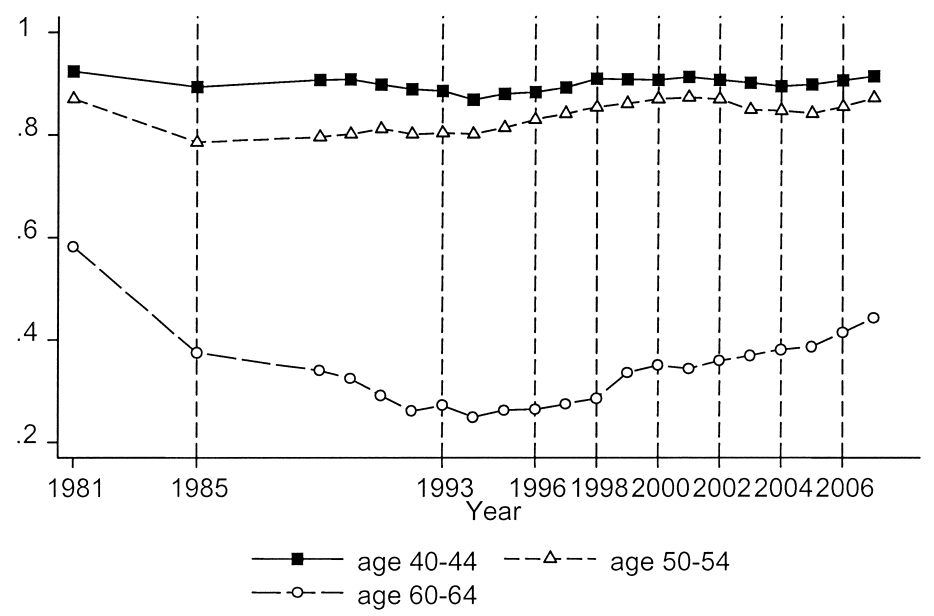

Fig. 12.14 Male employment rate by age group

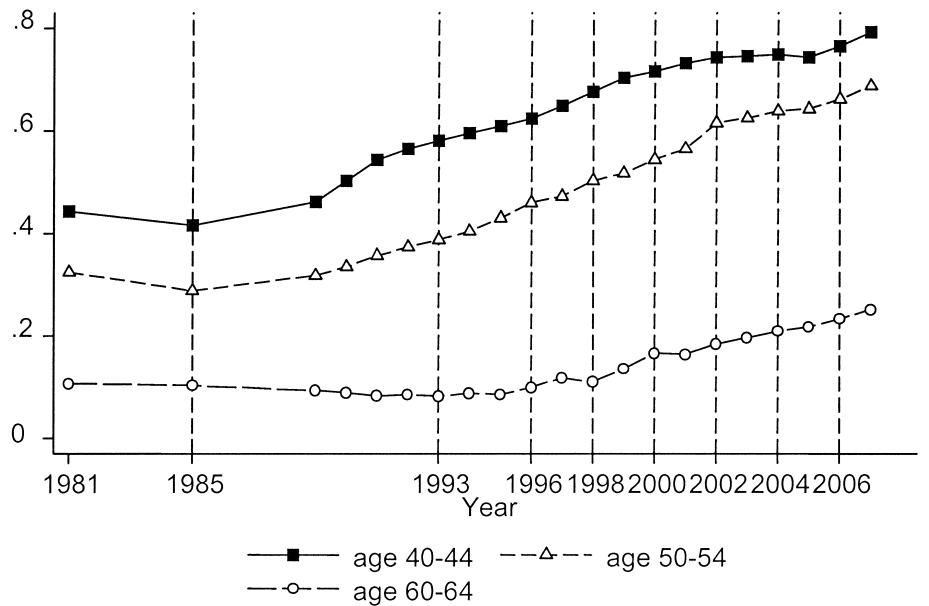

Fig. 12.15 Female employment rate by age group

show much less variation, with employment hovering close to 90 percent in the youngest age group and slightly lower in the age group fifty to fifty-four.

For women, the employment rates show clear cohort effects: employment starts its spectacular increase during the 1980s in the younger age groups, followed with some delay, and at a much lower level, by the oldest age group. Unemployment, starting off at very low levels, hovers between 5 and 10 percent after 1989 in all three age groups. The percentages not in the labor force again mainly reflect the trends in the employment rates by showing the opposite pattern. 


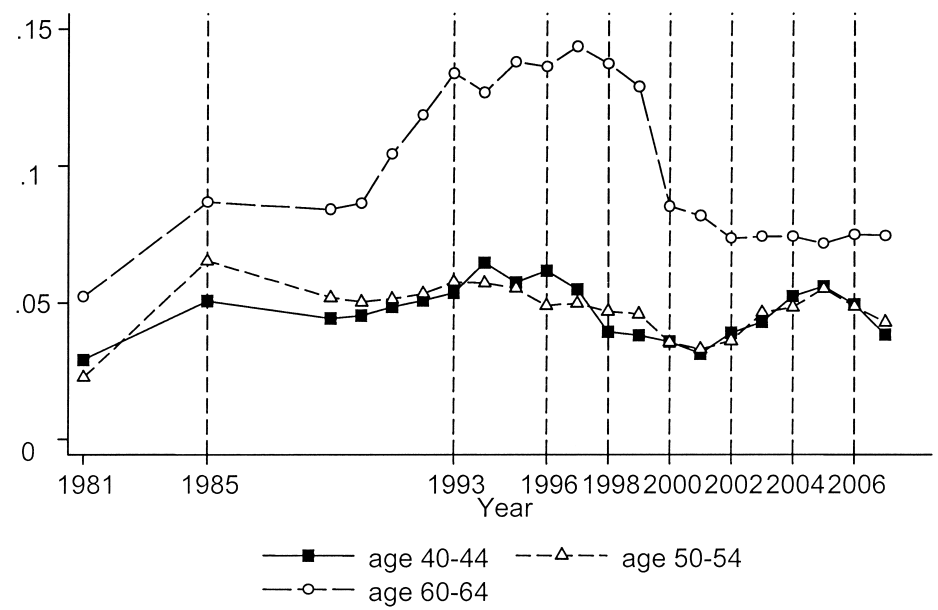

Fig. 12.16 Male unemployment rate by age group

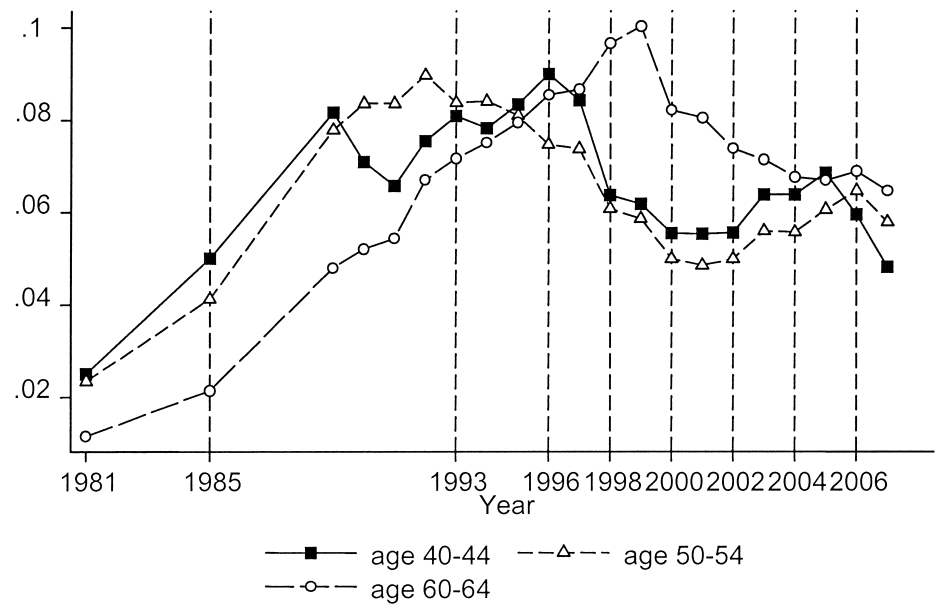

Fig. 12.17 Female unemployment rate by age group

If we separate out the DI recipients from men not in the labor force (figure 12.20), we note that whereas the latter statistic showed a steep increase in the oldest age group between 1981 and 1994, the number of DI recipients only increased moderately (from about 20 to 23 percent). On the other hand, a large part of the decrease in the number of men not in the labor force after 1994 in this age group is made up by a decrease in the number of DI recipients. For women, the DI rates do not show decreasing trends: they more or less appear to reflect the increasing labor force participation rates (see figure 12.21). 


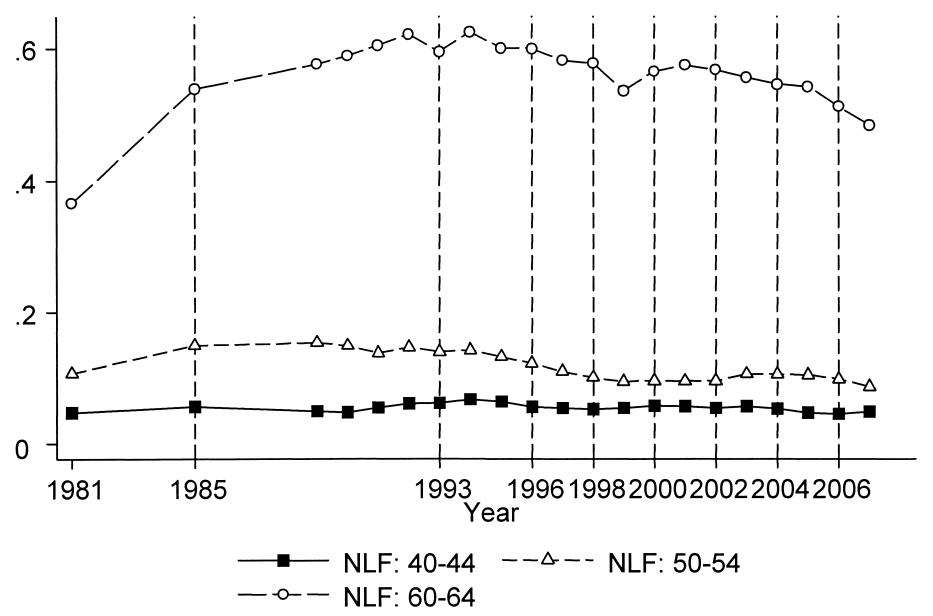

Fig. 12.18 Male not in labor force (NLF) by age group

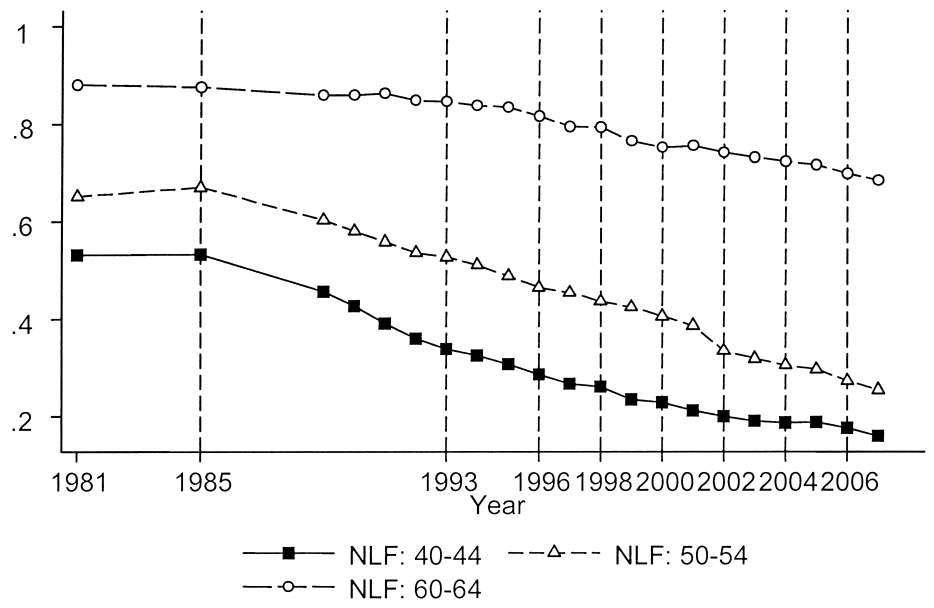

Fig. 12.19 Female not in labor force (NLF) by age group

\subsubsection{Historical Data on DI versus Health, Mortality}

Comparing mortality trends and DI receipt of men aged forty to fortyfour (figure 12.22), we notice that this age group showed an increase in the number of DI recipients between 1981 and 1994, despite the slightly decreasing mortality rate. After 1994, the decreasing mortality rate could be seen as one of the contributing factors to the decrease in the number of DI recipients. For the women in this age group, mortality and DI receipt show a negative correlation (figure 12.23), if any.

In the age group sixty to sixty-four, the pattern is comparable: for men 


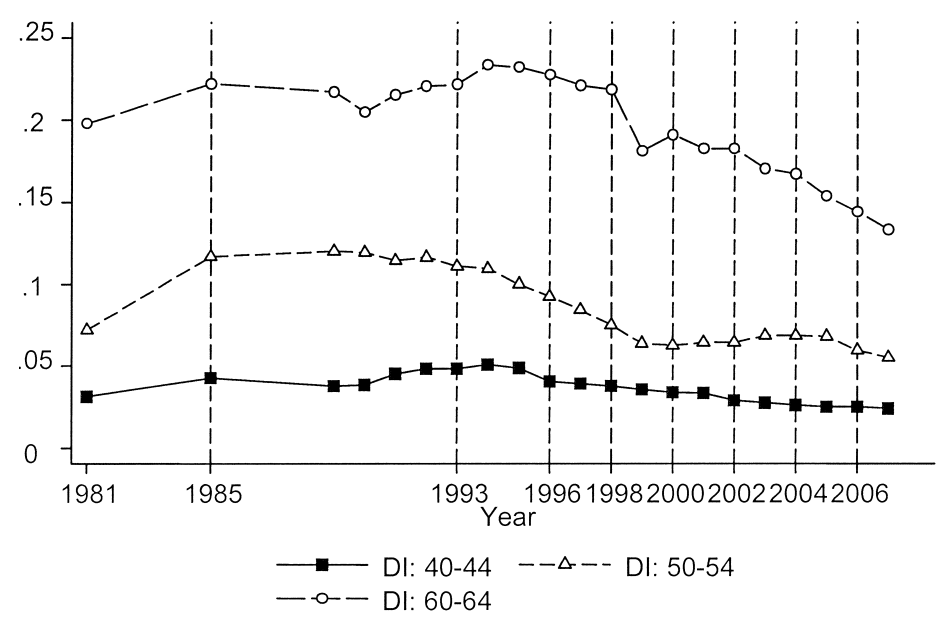

Fig. 12.20 Male disability rate by age group

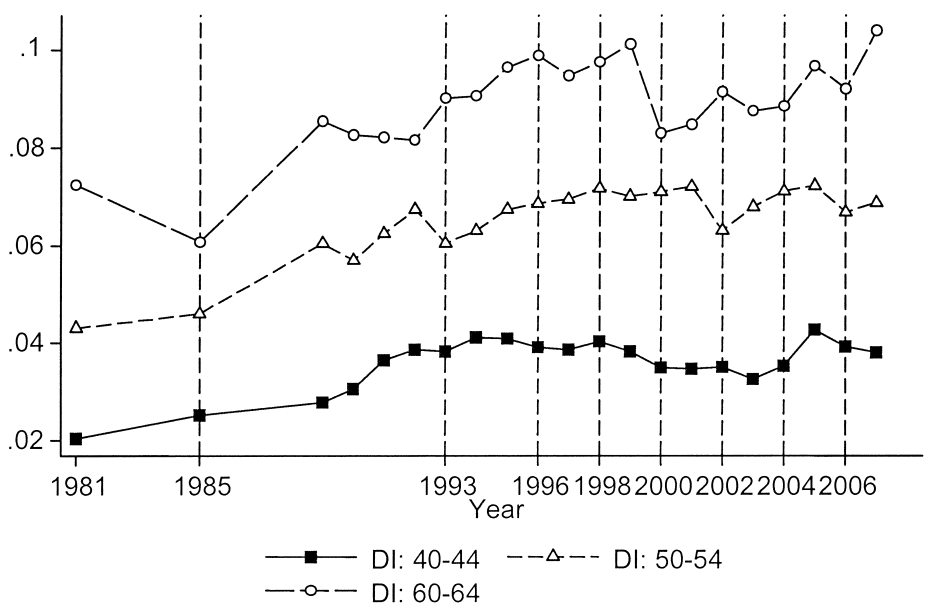

Fig. 12.21 Female disability rate by age group

(figure 12.24), DI and mortality show opposing trends until 1994 but both move downward afterward. For women (figure 12.25), DI and mortality show a negative correlation throughout the whole period. Both for this age group and for the age group forty to forty-four, the negative correlation would be the direct result of the cohort effects in female labor force participation. Female employment rises steadily during the period, and DI receipt rises with it. Because at the same time mortality decreases steadily, a negative correlation is the result.

For health, we only have a crude measure (the percentage of people with self-reported health good or better) for a broad age group (forty-five to 


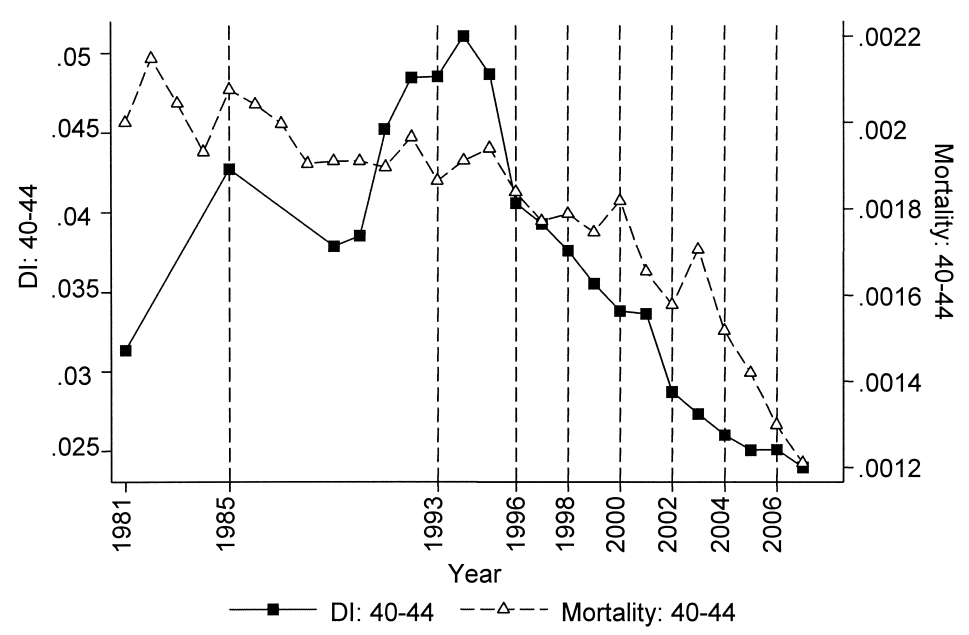

Fig. 12.22 Male mortality versus disability, aged forty to forty-four

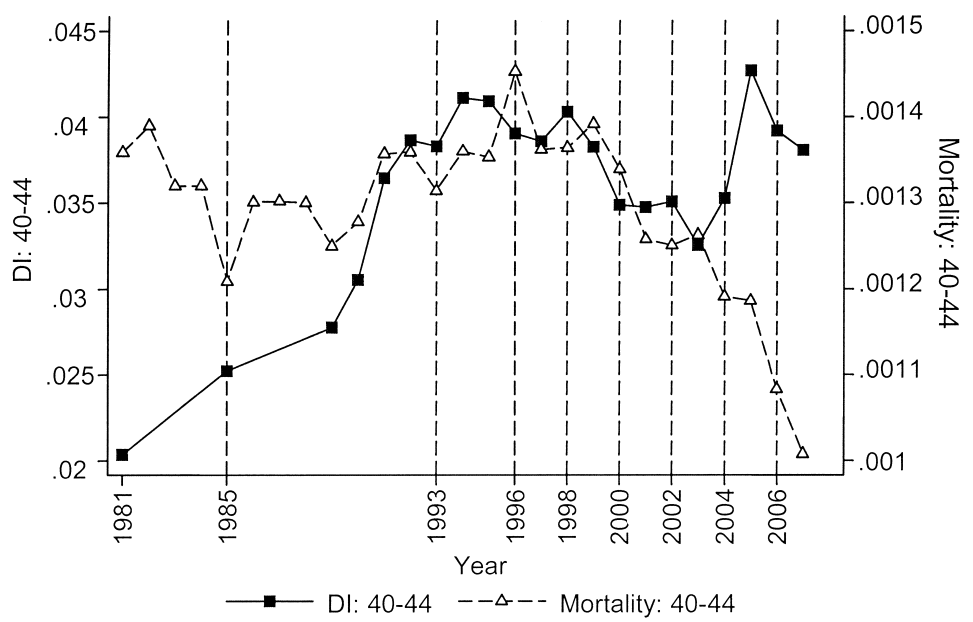

Fig. 12.23 Female mortality versus disability, aged forty to forty-four

sixty-four). For men, there is some indication that an improvement of the health measure coincides with a decrease in DI receipt. For women, there is no clear trend in the health measure, while DI receipt tends to increase slightly (see figures 12.26 and 12.27).

A final perspective is given by figure 12.28, which shows the difference between DI receipt in the age groups sixty to sixty-four and forty to fortyfour for men and women. Notably, for men, this difference is much higher than for women throughout the whole period. This probably does not really mean that disability prevalence increases much faster with age among men 


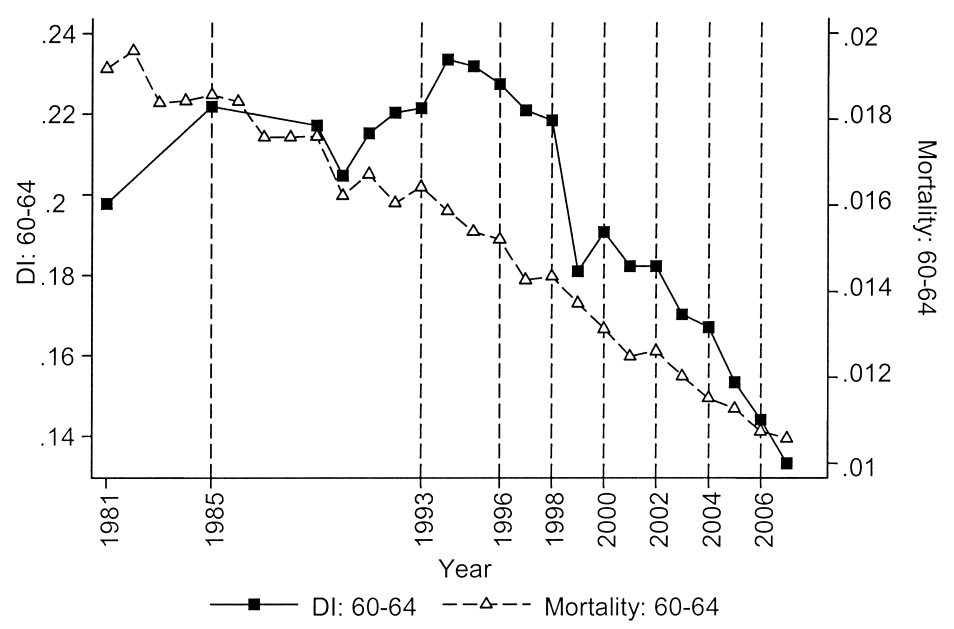

Fig. 12.24 Male mortality versus disability, aged sixty to sixty-four

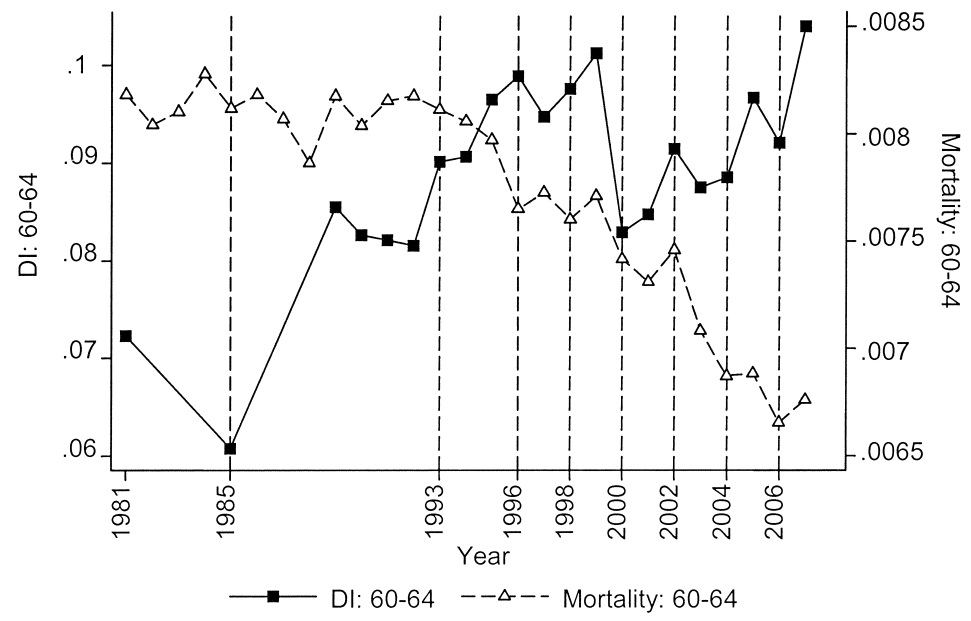

Fig. 12.25 Female mortality versus disability, aged sixty to sixty-four

than among women. More likely it is caused by the fact that women who left the labor market relying on the income of their spouse have no access to DI. The declining difference between men and women is indicative of the fact that more and more older women stay on the labor market. The fact that the difference between forty to forty-four-year-old men and sixty to sixty-fouryear-old men decreases at the end of the period suggests that the earlier, larger difference between these age groups is not really the result of older 


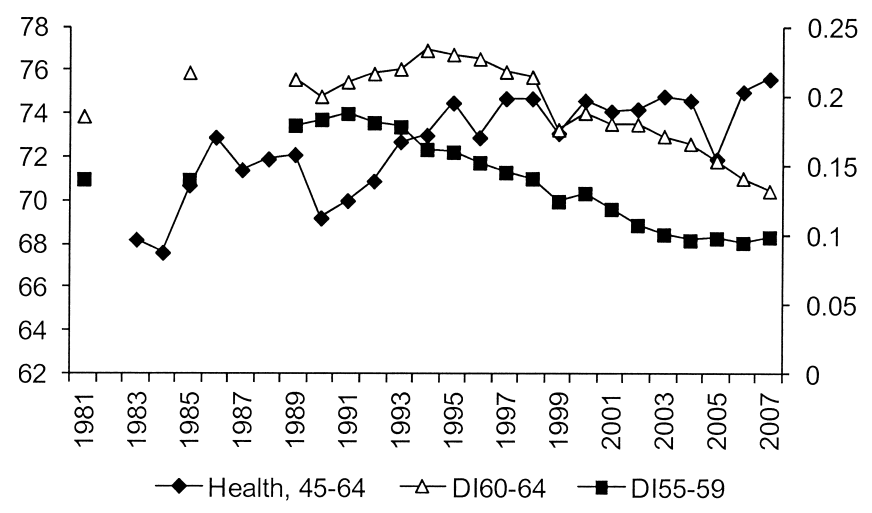

Fig. 12.26 Male self-rated health versus disability

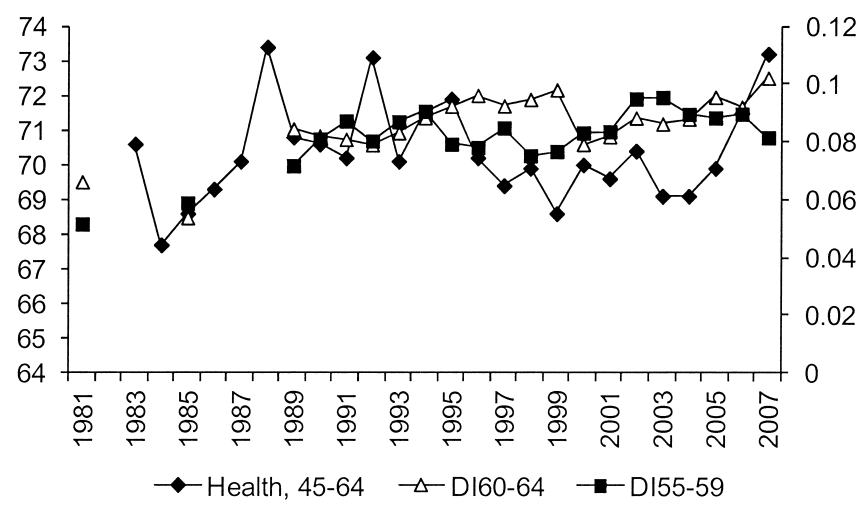

Fig. 12.27 Female self-rated health versus disability

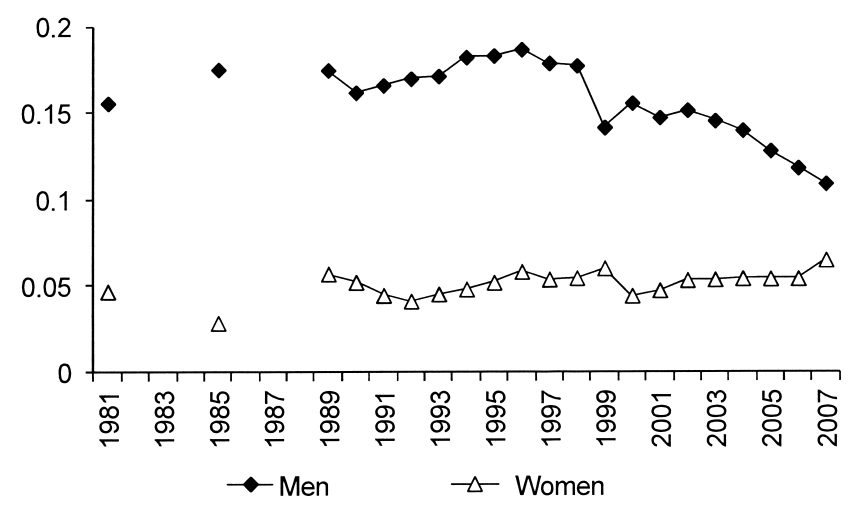

Fig. 12.28 Male and female disability, aged sixty to sixty-four less aged forty to forty-four 
people having a lower ability to work but is largely caused by the fact that it used to be easy to get access to DI for older men who wanted or were forced to leave the labor market before the statutory retirement age of sixty-five.

In summary, health and mortality do not seem to be strongly related to DI prevalence. At the end of the period, the reforms appear to be successful in causing a decrease in DI prevalence. In the next section, we will see if this result can be confirmed by a more rigorous quantitative analysis.

\subsection{An Explorative Empirical Analysis}

The empirical evidence presented in the preceding sections seems to suggest that DI receipt is unrelated to the general health of the population and that DI reforms may have led to relatively fewer older workers exiting the labor market through DI. In this section, we empirically investigate these issues using a regression model. Such an approach makes it possible to control for cyclical variation in the labor market exit rate and to quantify the impacts of health and policy reforms on the various pathways to retirement conditional on age and gender. The policy reforms are modeled using yeardummy variables indicating the reforms that have also been highlighted in the figures in the previous sections (see also table 12.1). The data are taken from the Income Panel Study of the Netherlands (see section 12.4). We select individuals who are fifty to sixty-three years of age and aggregate these data based on year, gender, and age category (fifty to fifty-four, fifty-five to fifty-nine, and sixty to sixty-three). ${ }^{3}$ Over the time period 1989 to 2006, we have 108 observations.

\subsubsection{Empirical Framework: A Simple Pathway Model}

Individuals can exit employment through the pathways Disability Insurance (DI), early retirement (ER), Unemployment Insurance (UI), or nonparticipation (NP). With individual level data, this can be modeled using a competing risk model. We use, however, aggregated data to carry out the empirical analysis. This means we do not have individual pathways to retirement but proportions of (groups of) people that choose certain pathways. We define $p_{a g t}^{c}$ as the proportion of employed individuals with age $a$ and gender $g$ that leave employment through pathway $c$ in year $t$. For a logittype model for each pathway, we can specify the following linear regression model:

$$
\ln \left(\frac{p_{a g t}^{c}}{1-p_{a g t}^{c}}\right)=\alpha_{0 c}+\sum_{j=1}^{k} \alpha_{c j} D_{j t}+\beta_{0 c} X_{a g}+\beta_{1 c} H_{a g t}+\beta_{2 c} \ln \left(E_{a g t}\right)+\varepsilon_{a g t}^{c},
$$

3. We exclude sixty-four-year-old persons as most often their employment contract is automatically terminated when they reach the statutory retirement age of sixty-five and they start receiving a state pension. 
where $c \in(\mathrm{DI}, \mathrm{ER}, \mathrm{UI}, \mathrm{NP}), t \in\{1989, \ldots, 2006\},{ }^{4}$ the $D_{j t}$ s are dummy variables indicating reforms (see table 12.1), $X_{a g}$ are explanatory variables (gender and age), $H_{a g t}$ is remaining healthy life expectancy, ${ }^{5}$ and $E_{a g t}$ is the total outflow from employment. In the estimation, we use the pathway nonparticipation (NP) as the reference category. ${ }^{6}$ The error term $\varepsilon_{a g t}^{c}$ is heteroskedastic, and this is taken into account when calculating the standard errors. For details on the estimation, we refer to Cameron and Trivedi (2005). We use an instrumental variables estimator to take into account that the total outflow from employment $E_{a g t}$ may, for instance, be influenced by unobserved variables also affecting a specific pathway. ${ }^{7}$ The additional instrument is total employment by age, gender, and year obtained from OECD statistics. The justification for choosing this additional instrument is that the outflow from employment will be positively related with total employment because the more people are employed, the more people are at risk of leaving employment, while we do not expect total employment to affect the different pathways once we control for total outflow from employment. ${ }^{8}$

\subsubsection{Empirical Results}

The first column of table 12.2 presents the estimation results of a linear regression model explaining the (logarithm of) total flow from employment. The remaining columns present estimation results for the model discussed in the preceding for each of the pathways. The total outflow from employment increases with age and is higher among women than men. The total outflow appears unrelated to health. The DI reform in 1996 and the reforms in 2006 are significantly and negatively associated with the outflow from employment, but there is no significant association between the other reforms and the outflow from employment.

Conditional on the total flow from employment and compared to male workers, female workers are less likely to exit employment through DI, ER, and UI and more likely to exit employment without own source of replacement income. With age, ER becomes relatively more important, and DI and UI become less important exit routes. In line with our conclusions drawn from the various figures in the preceding sections, we find no significant relationship between healthy life expectancy and the pathways to retirement.

4. Outflow is from $t->t+1$. We do not observe the outflow in 1981 and 1985 because the subsequent years are not in our data. Hence, 1989 is our first year, and 2006 is the last year in our "flow" sample.

5. Remaining healthy life expectancy is defined as the number of years a person of certain age and in a particular year is expected to live in good health where good health is defined as absence of chronic disease, absence of physical limitations, or perceived good health.

6. We use the normalization $p_{\text {agt }}^{\mathrm{NP}}=1-p_{\text {agt }}^{\mathrm{DI}}-p_{\text {agt }}^{\mathrm{ER}}-p_{\text {agt }}^{\mathrm{UI}}$.

7. Another possible bias may come from measurement error in IPO data. For this reason, we use an instrument based on OECD data.

8. We follow Bound, Jaeger, and Baker (1995) and present a test for whether the instrument has sufficient explanatory power (see table 12.2). 


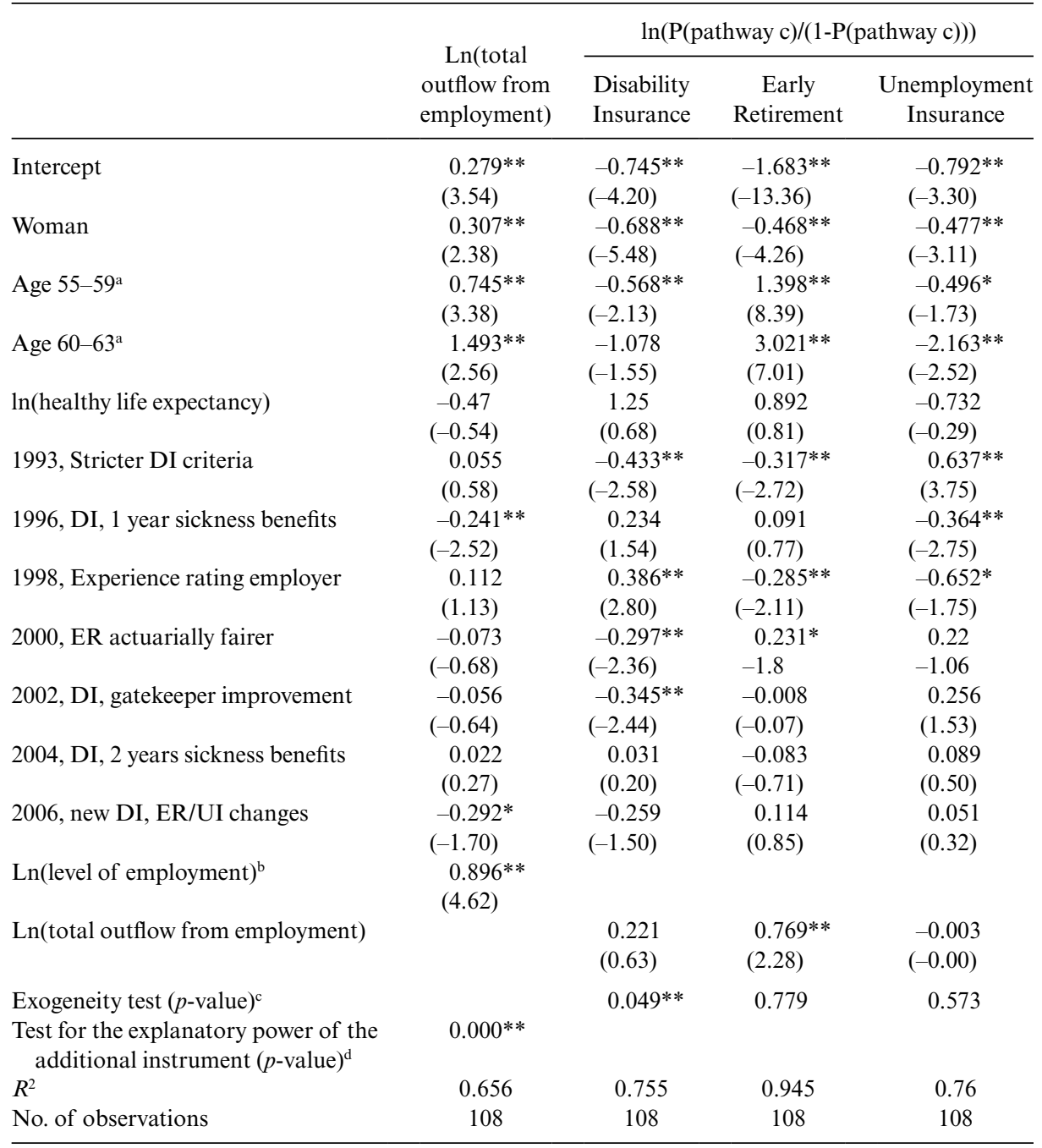

Note: In parentheses are $t$-values.

${ }^{a}$ Reference age $50-54$. The age dummies are jointly significant ( $p$-value $F$-test is 0.001 ).

${ }^{b} \mathrm{OECD}$ statistics, by age and gender.

${ }^{\mathrm{c}} H_{0}$ : total outflow from employment is exogenous.

${ }^{\mathrm{d}}$ The null-hypothesis is that the additional instrument $\operatorname{Ln}$ (level of employment) has no explanatory power.

$* * p<0.05$.

$* p<0.10$. 
The 1993 and 2002 DI reforms are associated with a lower exit probability into DI, while the 1998 reform (the introduction of experience rating) appears to have affected the exit probability to DI positively. We have no explanation for this latter finding, but the termination of experience rating in 2008 hints toward this indeed being an ineffective instrument for reducing DI inflow. A counterintuitive finding is the positive effect of the 2000 reform on ER and its negative impact on DI inflow. This may be the result of workers (and employers) making more use of ER in anticipation of further limitations on ER eligibility. In most cases, the coefficients of the reforms on the estimated probability to exit via unemployment have the opposite sign as the ones found for the probability to exit to DI, suggesting a possible substitution between these two routes.

To obtain further insights into these empirical results, table 12.3 presents the predicted percentage changes in the total outflow and the pathway probabilities due to a change in the explanatory variables. The total outflow from employment is 36 percent higher among women than men (first row). The outflow from employment more than quadruples for workers aged sixty to sixty-three compared to workers aged fifty to fifty-four, and, with age, workers are increasingly more likely to flow into early retirement than into disability or unemployment (rows [2] and [3]). Again, health appears to have no effect on the total outflow from employment and the pathways to retirement (row [4]). Total outflow from employment is not significantly associated with the outflow from employment into DI but is positively associated with the flow into ER. This suggests that when the total outflow from employment is high, for instance, as a result of a downturn in the economy, the exit route ER is relatively more frequently used.

Finally, the last row suggests that, cumulatively, the reforms have had substantial effects: they have reduced the total outflow from employment with 38 percent and, moreover, reduced the shares of the pathways into DI and ER with, respectively, 40 percent and 20 percent at the expense of an increase in the outflows into UI and nonparticipation ("Other") with, respectively, 17 percent and 53 percent.

\subsection{Conclusion}

The relatively generous and easily accessible DI benefit can be seen as an important institution contributing to the large numbers of workers retiring from the labor market at relatively early ages in the Netherlands. There are no indications that the high numbers of DI are related to high mortality rates or high percentages of persons living in bad health.

By a continuous series of reforms, the government has attempted to reverse the trend of ever expanding numbers of DI recipients. Until recently, these reforms did not result in much of a decrease in the number of DI recipients. 


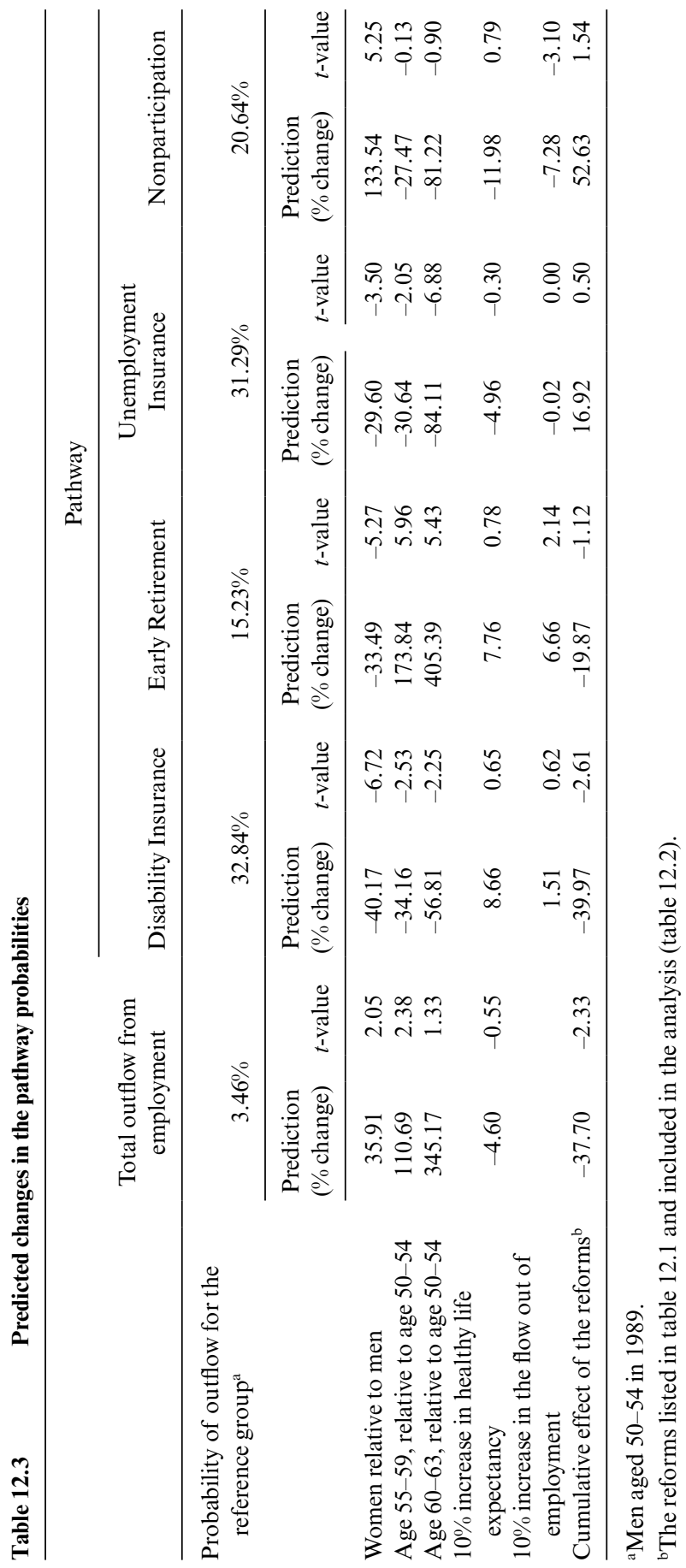


Despite the reforms, DI remained attractive and accessible. However, it is likely that without reforms, the number of DI recipients would have kept on increasing much further. The empirical analysis shows that several reforms to the DI, ER, and UI programs are related to the pathways to retirement. Notably, these reforms are found to be associated with reductions in the labor market exit rate of older workers and the percentage inflow into DI and ER. This has, arguably, contributed to the observed increased labor force participation rate among the fifty-five to sixty-four population from the mid-1990s onward.

\section{References}

Aarts, L. J. M., and P. R. de Jong. 1990. "Economic Aspects of Disability Behaviour." PhD diss., Erasmus University, Rotterdam.

Bound, J., D. A. Jaeger, and R. M. Baker. 1995. "Problems with Instrumental Variables Estimation When the Correlation between the Instruments and the Endogenous Explanatory Variable Is Weak." Journal of the American Statistical Association 90:443-50.

Cameron, A. C., and P. K. Trivedi. 2005. Microeconometrics, Methods and Applications. New York: Cambridge University Press.

Centraal Bureau voor de Statistiek (CBS). 2009. Documentatierapport Inkomenspanelonderzoek (IPO) (Documentation Income Panel Survey). Voorburg, the Netherlands: Centrum voor Beleidsstatistiek.

De Gier, E., R. Henke, and J. Vijgen. 2003. "The Dutch Disability Insurance Act (WAO) and the Role of Research in Policy Change." Amsterdam School for Social Science Research Working Paper no. 03/02.

Kapteyn, A., and K. de Vos. 1999. "Social Security and Retirement in the Netherlands." In Social Security and Retirement around the World, edited by Jonathan Gruber and David A. Wise, 269-304. Chicago: University of Chicago Press.

Kapteyn, A., K. de Vos, and A. Kalwij. 2010. "Early Retirement and Employment of the Young in the Netherlands." In Social Security Programs and Retirement around the World: The Relationship to Youth Employment, edited by Jonathan Gruber and David A. Wise, 243-59. Chicago: Chicago University Press.

Knoef, M., R. J. M. Alessie, and A. Kalwij. 2010. "Changes in the Income Distribution of the Dutch Elderly between 1989-2020: A Dynamic Microsimulation." Netspar Working Paper.

Stichting van de Arbeid. 2010. Pension Accord Spring 2010 (Pensioen Akkoord). www .stvda.nl. 